\title{
$\operatorname{arCOS} D E S I G N$
}

\section{Design e a construção de sentidos sobre questões de interesse público}

Clorisval Pereira Jr. (PUC-Rio, Brasil)

cjunior@gmail.com

Instituição: Pontifícia Universidade Católica do Rio de Janeiro

Endereço: Rua Marquês de São Vicente, 225 - Gávea, Rio de Janeiro 


\title{
Design e a construção de sentidos sobre questões de interesse público
}

Resumo: A partir do entendimento que o nosso futuro comum depende de uma transição para modos de vida mais sustentáveis, este artigo debate como as tecnologias digitais e a cultura de redes podem apoiar a construção de formas de organização e produção social, mais abertas, democráticas e participativas, e discute como o design pode apoiar essa transição através de práticas mais democráticas, críticas, especulativas e voltadas para inovação social. A partir desse contexto, destacamos a importância de práticas de design voltadas para a construção de sentidos e apresentamos dois experimentos de pesquisa-ação que buscam dar visibilidade a questões de interesse público.

Palavras-chave: Design para inovação social, Design para democracia, Design e participação social

\section{Design and sense-making of public interest issues}

\begin{abstract}
Based on the understanding that our common future depends on a transition to more sustainable ways of life, this article discusses how digital technologies and network culture can support the construction of more open, democratic and participatory forms of social organization and social production. It discusses how design can support this transition through more democratic, critical, speculative design practices, targeted on social innovation. From this context, we highlight the importance of design practices aimed at the sense-making and present two experiments of action research that seek to give visibility to public interest issues.
\end{abstract}

Keywords: Design for social innovation, Design for democracy, Design for social participation 


\section{O futuro comum}

Durante o século passado, acompanhamos o crescimento exponencial dos fluxos de oferta, demanda e consumo de bens industriais. Com a virada do milênio, o impacto social e ambiental resultante dos processos de industrialização passaram a ser observados não apenas em contextos localizados mas em escala planetária, levando diversos cientistas a considerar o início de uma nova época geológica caraterizada pelos efeitos da ação humana, o Antropoceno (Crutzen e Stoemer, 2000).

Dentre os principais impactos desses processos de industrialização podemos destacar: a desestabilização da camada de ozônio e o processo de aquecimento global, causados pela concentração de gases do efeito estufa na atmosfera, resultado do aumento da queima de combustíveis fosseis, da queima de biomassa das florestas, da emissão do metano produzido pela indústria pecuária e da emissão de fluo-carbonetos dos eletrodomésticos e aerossóis (UNFCC, 1992); um aumento sem precedentes nos últimos 2 bilhões de anos do nível de nitrogênio no solo, causado pelo uso massivo de fertilizantes (Vitousek, 1997); uma taxa de extinção de espécies 1000 vezes maior que a considerada normal levando à estimativa que até a metade deste século de $30 \%$ a $50 \%$ de todas as espécies eucariontes - que incluem as plantas, animais, insetos e fungos - estarão extintas (Thomas et al, 2004; Pimm et al., 2014); a presença de mais de 60.000 micro partículas de plástico em cada quilometro quadrado de oceano, resultado da má gestão de resíduos sólidos em terra (Cole et al., 2011; Jambeck et al., 2016); a concentração de mais de $80 \%$ população global vivendo em áreas urbanizadas que respondem por $70 \%$ da economia (GDP), $60 \%$ do consumo de energia, 70\% de emissões de gases do efeito estufa, e 70\% do lixo global (UN-HABITAT, 2016); o alarmante contexto de desigualdade social, onde $1 \%$ da população da população global detém a mesma riqueza que os demais $99 \%$, resultando em grandes fortunas acumuladas por poucos enquanto muitos ainda vivem em um cenário de pobreza extrema (OXFAM, 2017).

Por outro lado, críticas ao modelo de desenvolvimento adotado pelos países industrializados e reproduzido pelos países em desenvolvimento começaram a ser discutidas com maior ênfase a partir década de 1980. O relatório "Nosso Futuro Comum" (Brundtland, 1987), resultado do trabalho de uma comissão mundial organizada pela Organização das Nações Unidas (ONU), apontou a incompatibilidade dos padrões vigentes de produção e consumo, introduzindo o conceito de desenvolvimento sustentável como estratégia para se garantir recursos comuns para as gerações futuras. Desde então, diversas iniciativas 
desenvolvidas pela ONU, com a participação de diferentes países, organizações governamentais e organizações não governamentais, tem discutido e promovido ações afirmativas sobre a necessidade da transição para modos de desenvolvimento mais sustentáveis e para uma relação mais equilibrada com o meio ambiente. No entanto, apesar de algum progresso, ainda estamos muito longe de virar o jogo.

Ao descrever a história por trás do desenvolvimento do projeto Safecast - uma rede de ciência cidadã formada para monitorar o impacto ambiental do acidente na Central Nuclear de Fukushima Daiichi, causado pelo tsunami de 2011 no Japão - Joi Ito, diretor do MIT Media Lab e um dos fundadores do Safecast, destacou que a democratização da ciência é um passo fundamental para a solução dos problemas complexos da sociedade contemporânea, porque a transição para modos de vida mais sustentáveis não vai acontecer de cima para baixo, top-down (O’Brien, 2011).

O futuro comum e a transição para modos de vida mais sustentáveis dependem de uma maior participação da sociedade civil nas questões de interesse público. Para Benevides (1991), somente através do exercício da cidadania ativa que a sociedade civil poderá exercer algum poder sobre o Estado e sobre as corporações privadas em torno do mercado.

Ostrom (1990), primeira mulher a ganhar o prêmio Nobel de Economia, tem criticado políticas de gestão ambiental baseadas em intervenções do Estado e do mercado que não levam em conta a participação das comunidades locais. A partir de pesquisas com comunidades de pescadores e agricultores no Canadá, Suíça, Japão, Filipinas, África e Nepal, a autora defende a gestão de recursos comuns baseadas na capacidade de interlocução dos indivíduos e na possibilidade da participação na negociação das regras do jogo. Organizações cooperativas, colaborativas ou autogeridas, que privilegiam os conhecimentos locais e a participação comunitária para tomada de decisão e gestão de recursos comuns podem ser mais eficientes na gestão de recursos comuns que o Estado ou que grandes corporações privadas.

Para Dardot e Laval (2014), o comum não pode ser institucionalizado como um bem. Antes disso, são os arranjos sociais e culturais que determinam o que é comum e coletivo. O comum é um "princípio de atividade política constituído pela atividade específica da deliberação, julgamento, decisão e a aplicação de decisões". As coisas comuns surgem da interlocução, da participação no contrato social, da capacidade de autogestão, qualidades que não podem ser externalizadas pelo Estado ou pelo mercado. 
No entanto, ao mesmo tempo em que a constituição de arranjos sociais comuns e democráticos dependem da participação ativa dos indivíduos, produzir esses espaços funcionais de participação não é uma tarefa fácil (Theiss-Morse \& Hibbing, 2005).

No Brasil, a Constituição Cidadã de 1988 trouxe um novo modelo de democracia participativa para o país, baseada em uma concepção universalista dos direitos sociais e com importantes mecanismos democráticos de participação cidadã, tais como: o plebiscito, o referendo popular, a iniciativa popular de lei, a tribuna popular, a audiência pública, bem como os conselhos e assembleias populares. Esse modelo teve como pressuposto assegurar a ampliação do espaço decisório para outros grupos sociais, além dos políticos profissionais. (Teixeira, 2008). No entanto, esses espaços não encontraram seu lugar na estrutura do estado brasileiro. Os espaços participativos foram, em geral, contaminados pelo jogo político da formação de maioria eleitoral, e constituíram meros espaços subordinados, de "escuta forte", de institucionalidade paralela, sem renovar a arquitetura institucional. As experiências participativas e inovadoras no Brasil ficaram à periferia do sistema, afetando pontualmente políticas setoriais, a depender da vontade política dos governos e da pressão da sociedade (Teixeira, 2008).

Com a transformação da sociedade industrial em sociedade da informação se estabelecem novos territórios de participação e produção social onde a geração, o processamento e a transmissão da informação e do conhecimento se convertem em fontes de produtividade e de poder (Castells, 1999). Este novo cenário abre novos campos de possibilidades. Por um lado o domínio da tecnologia pode acelerar os processos de globalização e industrialização e reforçar estruturas de poder do estado e do mercado, marginalizando grupos sociais excluídos das redes de informação (Castells, 2004). Por outro lado, a emergência da cultura do sofware-livre e da cultura de redes abre possibilidades de formação de organizações sociais descentralizadas, sem hierarquia rígida, baseadas na cooperação e no compartilhamento de recursos comuns e não proprietários que poderiam apontar para novos cenários de democracia digital (Lessig, 2004; Benkler, 2006; Tapscott \& Williams, 2006; Shirky, 2008).

A partir deste contexto, nos interessa discutir o papel do design na produção do nosso futuro comum e como o design pode apoiar a transição para modos de vida mais sustentáveis. 


\section{Design e transição para modos de vida mais sustentáveis}

Ao longo do século XX o campo do design se desenvolveu, em grande parte, associado aos processos de modernização e industrialização. A expertise criativa de designers foi amplamente utilizada não apenas para dar forma produtos industriais de consumo como também para estimular esse consumo através de grandes campanhas de marketing e publicidade.

Por outro lado, a partir dos 1960 o movimento de crítica aos efeitos da industrialização e o debate sobre formas mais sustentáveis de desenvolvimento começa a tomar corpo também no campo do design. Diversos profissionais e teóricos do campo passaram a chamar a atenção para a responsabilidade social dos designers e para a importância de se propor uma ação mais afirmativa, ideológica, visando a sustentabilidade, a autonomia e a consciência social (Garland, 1964; Selle, 1973; Papanek, 1976; Bonsiepe, 1978, 1983; Margolin, 1989; Frascara, 1997; Deforges, 1999). Esta mudança de paradigma no campo do design aspira uma prática que não seja mais parte do problema, mas sim parte da solução para um futuro comum mais sustentável.

Para Manzini (2008), a transição para modos de vida mais sustentáveis virá de uma "descontinuidade sistêmica", de uma mudança de modelo mental, da transformação das sociedades que valorizam índices de crescimento em sociedades capazes de reduzir os seus níveis de produção e consumo. Para o autor, essa transição dependerá de um processo difuso de aprendizagem social, que será operada inicialmente em pequenos contextos locais, em "microescalas", e somente depois será percebida em contextos globais, em "macroescalas". Essa transição será liderada por pequenas iniciativas locais, por comunidades criativas (Meroni, 2007), que emergem de baixo para cima, bottom-up, rompendo com padrões consolidados, apresentando novos comportamentos produtivos e configurando experimentos sociais de futuros possíveis.

Manzini (2015) destaca que o design pode desempenhar um papel estratégico na formação e no trabalho dessas novas organizações sociais, democráticas e participativas, que irão liderar os processos de mudança social em direção à sustentabilidade. Nesse sentido, o autor defende práticas de design que sejam mais orientadas para a inovação social do que para a inovação tecnológica e destaca que o design não apenas solucionará problemas mas também apoiará a construção de novos sentidos sobre questões de interesse público.

Irwin (2015) também destaca o papel do design na transição para modos de vida mais sustentáveis. Nesse contexto, o design deve estar 
associado a teorias de mudança e ter o papel de produzir visões de novos modos de vida, que são ao mesmo tempo baseados no conhecimento local e conectados com o global através de uma cultura de compartilhamento de informação e conhecimento. Para a autora, o campo do design precisa ser ocupado por posturas e modelos mentais de abertura e colaboração, além de desenvolver capacidades para lidar com temas complexos, incertos e controversos, que desafiem os atuais paradigmas políticos e socioeconômicos e que destaquem as interconexões e relações simbióticas dos ecossistemas nos quais estamos inseridos. Os novos modos de fazer design irão incorporar processos que apoiam iniciativas locais, em fases iniciais de ideia e maturação, amplificam os recursos e as relações comuns, e apoiam a construção de alianças, através da transdiciplinaridade e de processos de co-design.

Neste cenário de transição, o design deixa de lado o determinismo e a racionalidade característica do modo de produção industrial, e se aproxima de práticas mais democráticas, participativas, críticas e voltadas para a inovação social.

Apoiando processos de inovação social, o design se concentra em ideias, estratégias, produtos, serviços, modelos e organizações, que fortalecem a capacidade de ação social, criam novas relações e formas de colaboração, ao mesmo tempo em que são orientados às necessidade sociais em torno do bem comum (Mulgan, 2010). A prática do design passa a gerar soluções criativas para problemas complexos, que em geral não são atendidos por outros processos institucionalizados (Cipolla e Moura, 2012).

Práticas de design participativo permitem a projeção de futuros alternativos, "design for use before use" (Ehn, 2008). Experimentos de design participativo configuram práticas de design democrático, quebram o isolamento do designer, da atuação restrita à prancheta do estúdio e levam o projeto para o mundo real. Mais ainda, permitem que a inteligência e os conhecimentos locais possam ser incorporados ao projeto, de forma colaborativa.

Práticas de design críticas e especulativas permitem apresentar questões abstratas e de interesse público sob a forma de produtos hipotéticos, cenários e simulações que permitem o envolvimento com questões de interesse público por meio da construção de controvérsias projetadas para produzir engajamento cívico e conscientização (Dunne and Raby, 2005, 2013). Essas abordagens podem explorar táticas alternativas e não-dogmáticas para conceber visões, objetivos e desejos que não são expressos nas estratégias que normalmente prescrevem comportamentos e cursos de ação dentro de estruturas constituídas de poder (DiSalvo, 2012). 
Autores como Thorpe (2008), Fuad Luke (2009), Meroni et al. (2013), defendem a prática do design como ativismo para empoderar comunidades criativas a construir estratégias ou modelos de serviços, que permitam prototipar novas realidades, criar novos modos de vida e promover de fato a inovação social.

Atualmente podemos notar intensos processos de inovação social sendo catalisados por uma crescente demanda por soluções para os graves problemas sociais e ambientais e pela emergência das novas tecnologias redes e mídias digitais. Segundo Manzini (2015), ao proporcionar novas formas de conexão e de colaboração, as tecnologias digitais estão permitindo a emergência de um número maior de iniciativas de inovação social voltadas para solucionar os crescentes problemas sociais e ambientais causados pela industrialização e pelo aumento populacional.

Dessa forma, é importante discutir algumas perspectivas para o design nestes novos territórios de inovação social digital.

\section{Design e inovação social digital}

Um grande número de soluções e serviços baseados em tecnologias digitais estão trazendo formas novas e potentes para conectar cidadãos com seus vizinhos, com a cidade e com o Governo (Pahlka, 2013). Essas soluções, que passam a ser caracterizadas como tecnologias cívicas, teriam como papel principal a colaboração entre cidadãos e administração pública a partir do incremento qualitativo e quantitativo da comunicação entre ambas as partes e da promoção de maior satisfação com o uso dos serviços públicos.

Um estudo realizado pela Knight Foundation (Patel et al, 2013), mapeou o panorama de inovação em tecnologias cívicas nos EUA e Europa, entre os anos 2011 e 2013, com objetivo de extrair insights sobre o futuro desse cenário, sobre a eficácia das tecnologias cívicas e sobre formas de medir o seu impacto. Os pesquisadores da Knight Foundation identificaram que as tecnologias cívicas são resultado de uma convergência de iniciativas de participação cidadã sendo promovidas por organizações da sociedade civil em diferentes campos de atuação, tais como: acesso e transparência de dados governamentais; mobilização comunitária em torno de causas e campanhas; redes e fóruns comunitários sobre temas de interesse público; redes de consumo colaborativo e de compartilhamento de recursos; ou projetos de financiamento colaborativo voltados para serviços e espaços públicos.

Por outro lado, um estudo desenvolvido pela Nesta, uma fundação de inovação no Reino Unido, em parceria com a Waag Society, um instituto 
de arte, ciência e tecnologia na Holanda, e financiado pela Comissão Européia, procurou mapear o cenário global de inovação social digital na Comunidade Européia com foco em projetos onde a tecnologia digital é utilizada com o objetivo de promover impacto social através de iniciativas baseadas em hardware aberto, redes abertas, dados abertos e conhecimento aberto (Open Hardware, Open Networks, Open Data e Open Knowledge). Este ecossistema de conhecimento aberto e tecnologias abertas está potencializando a ação de organizações e projetos de inovação social digital, participação democrática e inclusão social (Bria et al., 2014).

Para entender como a sociedade civil no Brasil está utilizando tecnologias de informação e comunicação para conectar cidadãos e comunidades em torno de questões de interesse comum e modos de vida mais sustentáveis, realizamos um mapeamento das tecnologias cívicas e das iniciativas de inovação social digital no Brasil como parte da pesquisa de doutorado realizada no Programa de Pós-graduação em Design da PUC-Rio (Pereira Junior, 2017).

Ao todo, foram mapeadas 106 plataformas de tecnologias cívicas implantadas no Brasil entre os anos 2010 e 2015. O mapeamento foi estruturado com base em uma taxonomia de classificação que é baseada na revisão dos quadros conceituais expostos no panorama das tecnologias cívicas, realizado pela Knight Foundation (Patel et al., 2013), e no mapeamento de iniciativas de inovação social digital, realizado pela Nesta/Comissão Européia (Bria el al., 2014). Ao realizar um cruzamento entre os dois quadros de análise, evidenciamos um recorte do campo das tecnologias cívicas destacando as iniciativas que privilegiam processos de inovação social digital, isto é, iniciativas desenvolvidas por comunidades criativas que utilizam conhecimento aberto, tecnologias abertas e produção social colaborativa para o bem comum (Figura 01).

Considerando o papel do design nestas organizações, observamos a importância de se discutir práticas, estratégias e táticas de design que sejam adequadas com a cultura de dados abertos, tecnologias abertas, redes abertas e conhecimento aberto. Mais ainda, considerando o cenário de transição para modos de vida mais sustentáveis, consideramos importante discutir também práticas de design que sejam orientadas não apenas para solucionar problemas mas também para construir sentidos sobre problemas sociais cada vez mais complexos. 


\section{Design para construção de sentidos sobre questões de interesse público}

Conforme destacado por Manzini (2015), uma contribuição fundamental do campo do design para tornar o ecossistema de inovação social mais ativo, colaborativo e sustentável, é tornar esse ecossistema mais visível (Manzini, 2015, p. 121).

Grande parte das iniciativas observadas no mapeamento das tecnologias cívicas e inovação social digital no Brasil estão utilizando estratégias de visualização de dados e de mapeamento colaborativo para dar visibilidade, para tangibilizar e para construir sentidos sobre questões de interesse público (Pereira Junior, 2017).

Com isso em mente, procuramos explorar práticas, métodos e técnicas de design de mídias digitais, que utilizam estratégias de visualização de dados e mapeamento colaborativo, para construir sentidos sobre questões de interesse público através de uma abordagem exploratória de pesquisa-ação onde realizamos experimentos com métodos colaborativos e experimentais de coleta, agregação e visualização de dados para a produção de narrativas e cartografias sobre questões de interesse público.

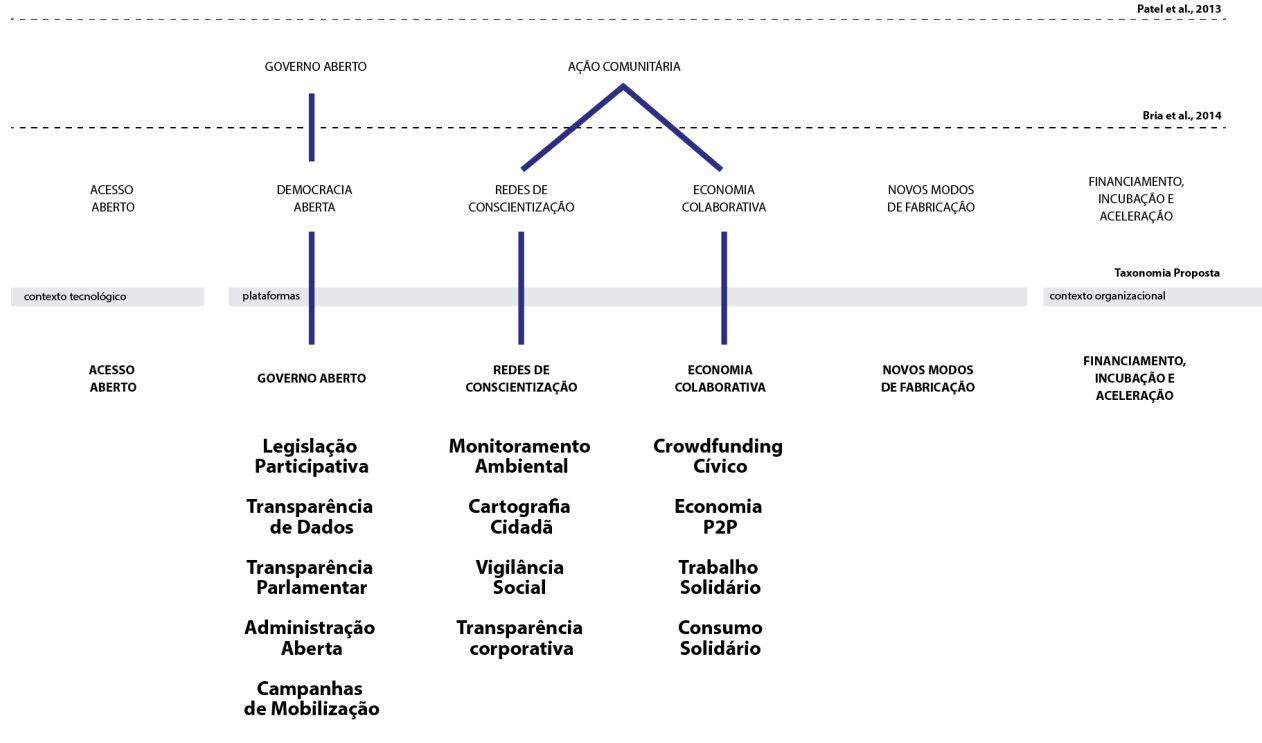

Figura 1. Framework proposto para análise das tecnologias cívicas no Brasil sob a ótica da inovação social digital.

Nossa intenção com estes experimentos de pesquisa-ação foi explorar o campo emergente da geração cidadã de dados, com práticas de design democrático, participativo e crítico, apoiado por dados abertos, tecnologias abertas e conhecimento aberto, assim como explorar 
perspectivas para o design de mídias digitais orientado para a construção de sentidos no contexto das iniciativas de tecnologias cívicas e de inovação social digital.

A seguir apresentamos um relato de 2 casos dessas experiências de pesquisa-ação.

\subsection{Cartografia dos desejos dos garis}

A cartografia dos desejos dos garis foi um experimento sobre como tornar visível questões de interesse público. O experimento foi realizado no escopo na disciplina "Práticas Criativas Colaborativas - Desafios Para o Design", coordenado pelas professoras Barbara Szaniecki e Talita Tibola, no Programa de Pós-Gradução e Design da ESDI/UERJ, e contou com uma interação junto aos Círculos da Cidadania. O experimento teve como objetivo dar visibilidade aos discursos, sonhos e desejos da classe dos garis do Rio de Janeiro, e foi realizado em um evento organizado pelos garis em maio de 2016, no Parque Madureira.

Partindo de questões sobre o que é, como se percebe, como se dá, como se faz, como se constrói a coisa pública, no artigo "Design and the constructions of Public", DiSalvo (2009) discute como o design pode contribuir para a construção da coisa pública à luz do pensamento de Dewey e Latour. Dewey estava interessado em como a coisa pública é constituída, para poder investigar as potencialidades e condições que possibilitam ou inibem a ação política coletiva nos tempos contemporâneos. Na exposição e livro "A coisa pública: Atmosferas da democracia”, Latour e Weibel (2005) retomam as indagações de Dewey, e perguntam "como as coisas são feitas públicas", adicionando a questão complementar "como o público é feito a partir das coisas".

Para Dewey e Latour, a coisa pública é emergente, está em constante formação. E esse entendimento da coisa pública não pode estar dissociado da materialidade concreta dos fatos, situações e experiências da vida cotidiana. A Teoria Ator-Rede considera o contexto sócio-material e trata das agregações emergentes de pessoas, objetos, coisas, que determinam as questões de fato e questões de interesse que formam a coisa pública.

Para DiSalvo (2009), uma forma do design contribuir para a construção da coisa pública seria através da utilização de táticas de rastreamento, que podem revelar e expor as estruturas subjacentes dessas agregações, dessas redes sócio-materiais, das ações, conceitos e valores que formam a coisa pública. 
Binder et al. (2015) apontam a potencialidade do encontro produtivo entre a Teoria Ator-Rede com práticas de co-design, e sugerem a emergência de "Experimentos de Design Democrático", como uma forma de se expandir as práticas de design participativo e co-design para contextos mais amplos de “democracia em ação”, abordando questões relacionadas a cidadania e participação pública. Para os autores, essa é uma chamada para um design que privilegie menos visões utópicas de futuros sem atrito, e que explane as condições sócio-materiais necessárias para um engajamento direto com questões controversas, contradições, oposições e desacordos.

A proposta da Barraca dos Desejos funcionou como um dispositivo sócio-técnico - lúdico e aberto - utilizado para mediar uma coleta de dados, desejos, sonhos e reivindicações dos garis de forma criativa, tal como numa brincadeira, em que o designer assume o papel de barraqueiro e o visitante da barraca troca um doce por um desejo (Figura 3). A experiência funcionou como um diálogo de design mediado por um jogo de participação (Brandt et al., 2008). Os desejos foram anotados em papel e depois estruturados em uma planilha de dados no software Microsoft Excel.

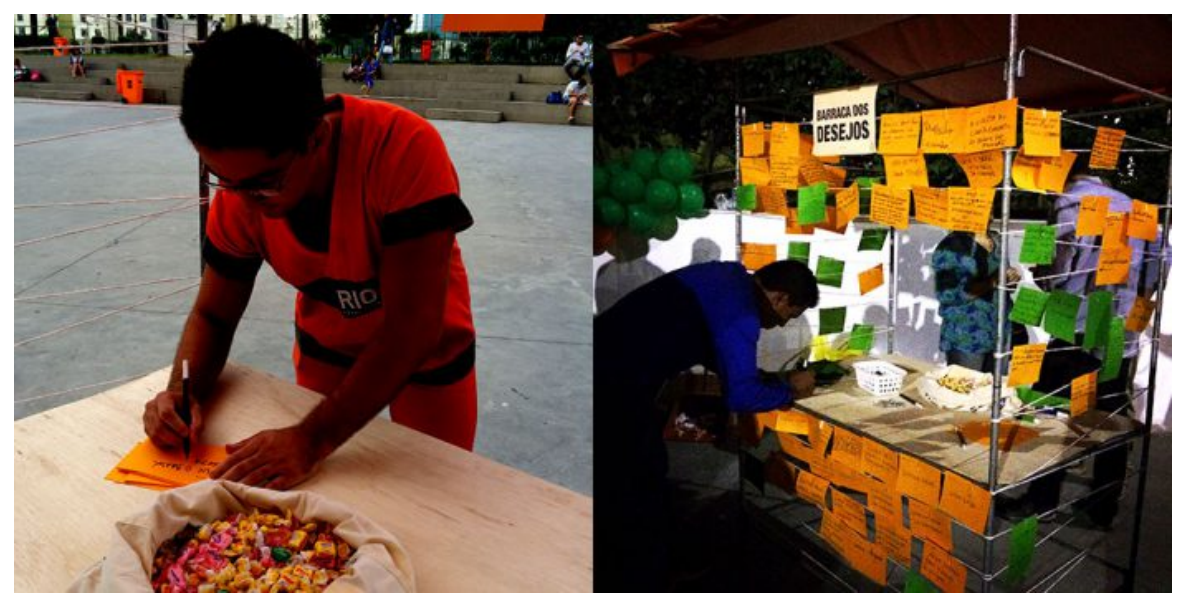

Figura 2. Barraca dos desejos.

Em seguida, foi utilizado o software de visualização de redes Gephi, para desenvolver um gráfico com os discursos subjacentes aos desejos dos garis (Figura 4). Cada desejo individual foi associado a duas categorias de nós/hubs: os atores dos desejos (Gari, Agente de Saúde Ambiental, Comlurb, Políticos, Sociedade); e os temas dos desejos (Sonhos, Direitos, Oportunidades, Mobilização). 


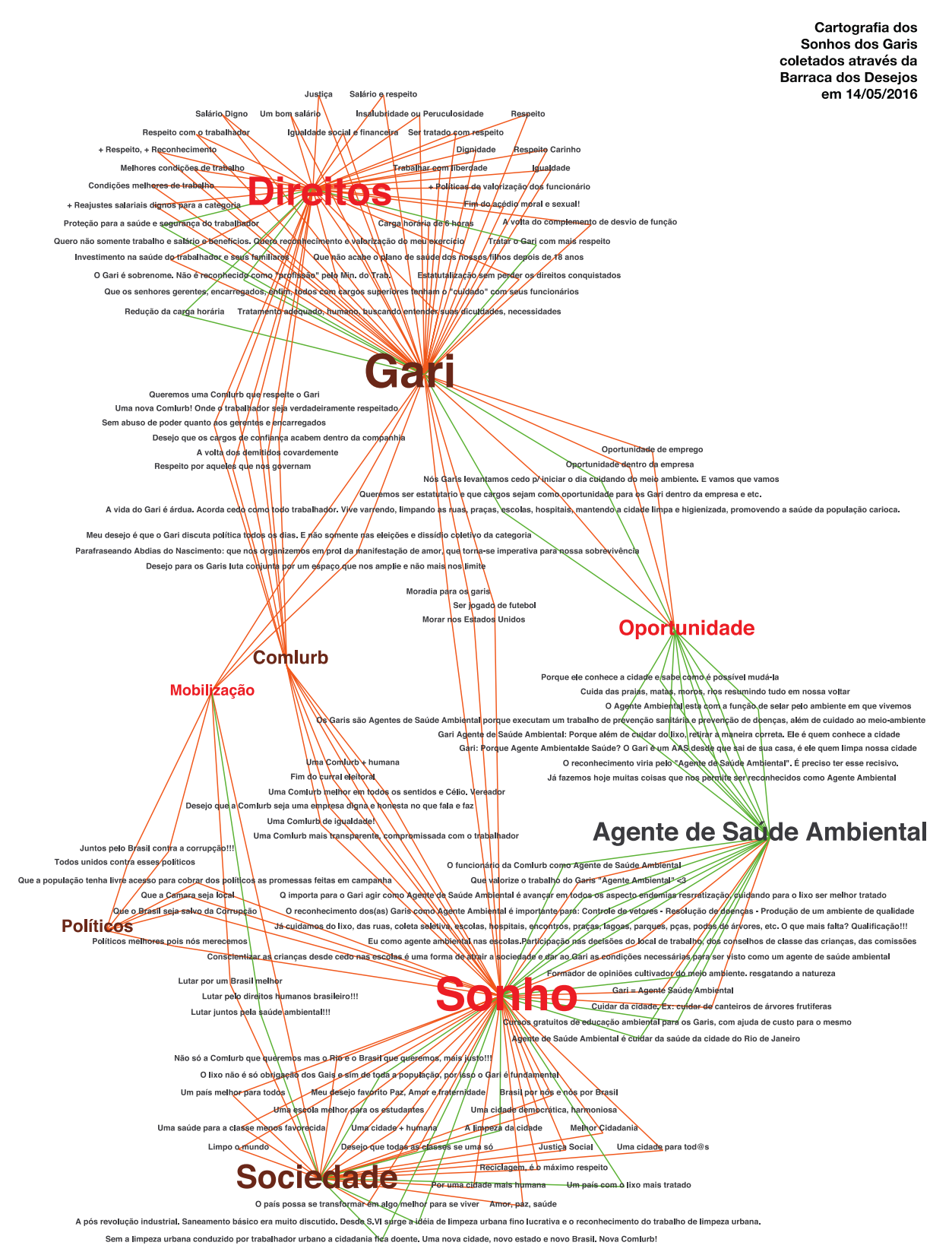

Figura 3. Cartografia dos desejos dos garis.

\subsection{Gambiarras no Centro do Rio de Janeiro}

Este experimento foi realizado em um workshop de mapeamento colaborativo na Escola Superior de Desenho Industrial (ESDI), realizado a convite do professor Mauro Pinheiro, em novembro de 2016.

A Web 2.0 trouxe a participação dos usuários para a geração de conteúdos online. Nesse contexto, observa-se a emergência de diversas 
plataformas de mapeamento colaborativo que passam a oferecer ferramentas para que diferentes grupos sociais possam mapear suas próprias comunidades e refletir sobre problemas de gestão e de planejamento urbano, apoiando os processos de tomada de decisão para formulação de soluções e construção de discursos (Gillavry, 2006; Goodchild, 2007; Cardone et al, 2013; See et al, 2013).

Tomando essa abordagem de mapeamento colaborativo, procuramos desenvolver um método de mapeamento que se mostrasse interessante para atividades de coleta de dados em campo. A proposta do Workshop levou em consideração técnicas de psicogeografia baseadas na teoria da deriva (Debord, 1958) para percorrer as ruas do centro da cidade do Rio de Janeiro procurando ocorrências de gambiarras urbanas, artefatos ou soluções improvisadas de convivência com o espaço urbano (Figura 4).

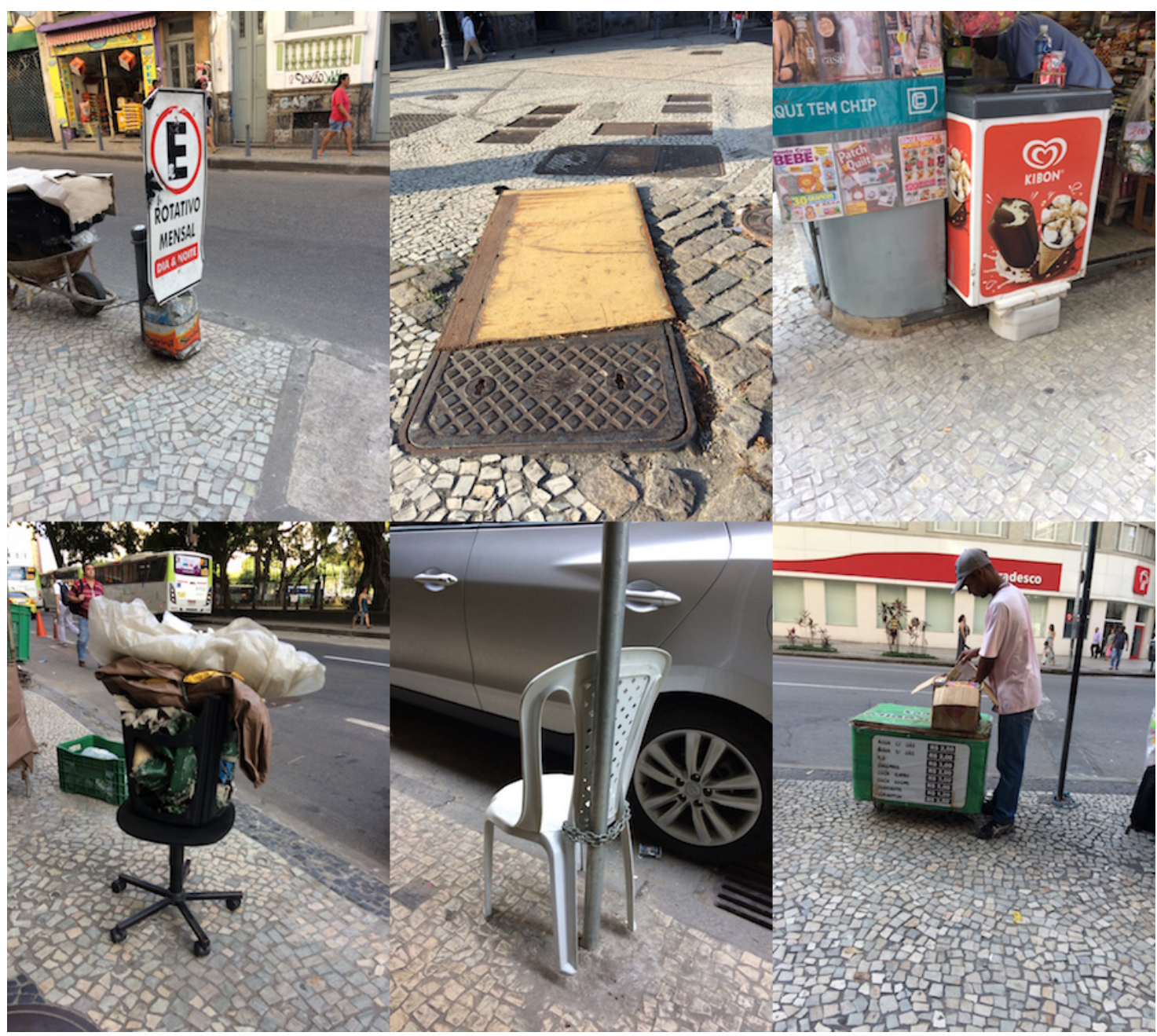

Figura 4. Fotografias de gambiarras capturadas com smartphones. 
Para realizar o mapeamento, as ocorrências foram fotografadas com smartphones e publicadas na plataforma Twitter com a geolocalização ativada. Em seguida, os dados e imagens foram extraídos da plataforma Twitter utilizando um script PHP para acessar a API REST do Twitter. Os dados foram agregados em um mapa digital através da plataforma Carto (Figura 5).

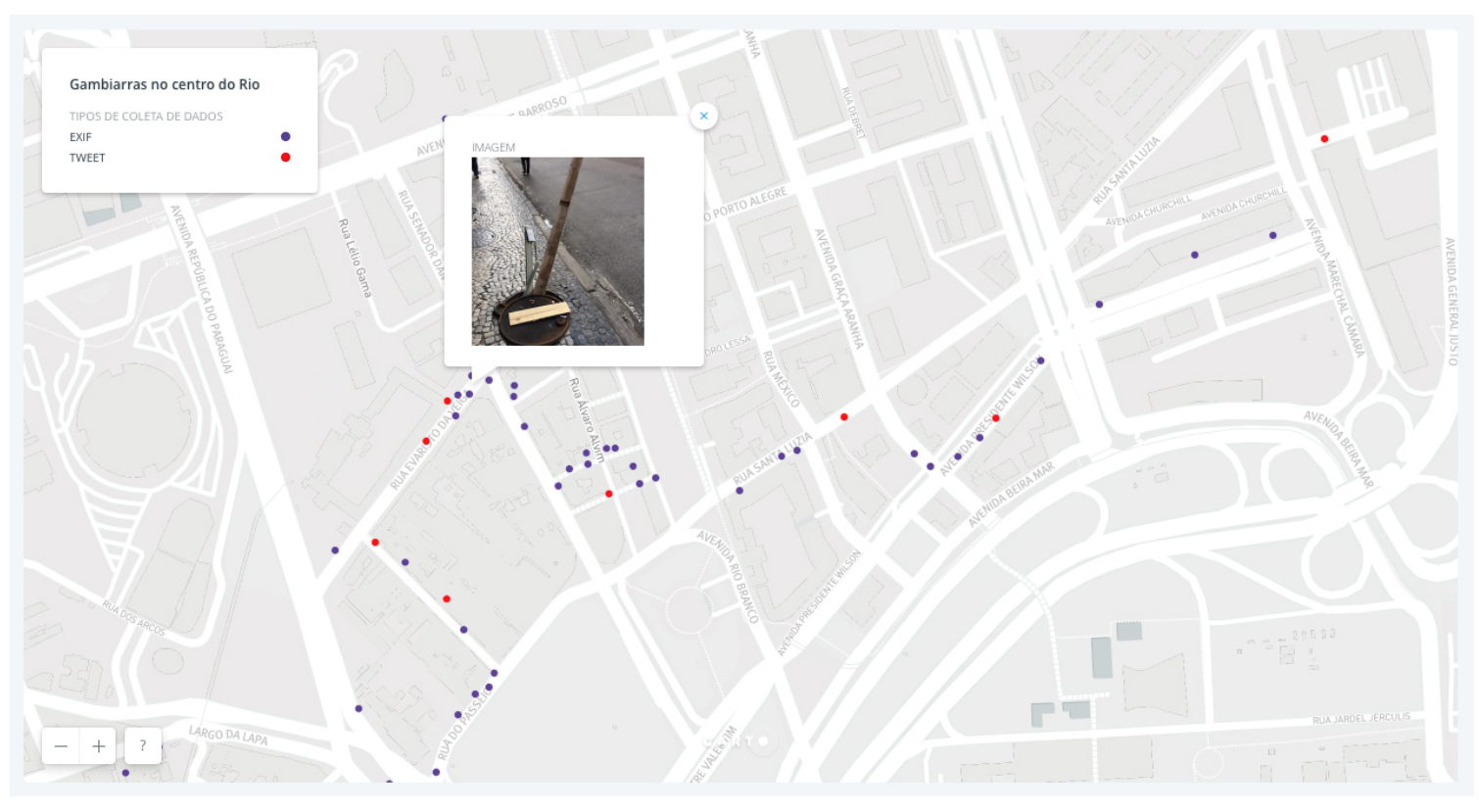

Figura 5. Mapeamento colaborativo de gambiarras, como extração de dados do Twitter.

\section{Conclusão}

O design pode apoiar estratégias de construção do comum através de processos de construção de sentidos sobre questões de interesse público. Ao expor e revelar as estruturas subjacentes das agregações, das redes sóciotécnicas, das ações, conceitos e valores que formam a coisa pública, o design pode contribuir para a construção do comum (DiSalvo, 2009). As práticas de design participativo e co-design podem ser expandidas para contextos mais amplos de "democracia em ação", abordando questões relacionadas a cidadania e participação pública através do engajamento direto com questões controversas, contradições, oposições e desacordos (Binder et al., 2015). 
Partindo de uma abordagem de pesquisa-ação com métodos de visualização de dados e mapeamento colaborativo, foi possível explorar práticas abertas, democráticas, participativas e críticas de design de mídias digitais, que podem apoiar processos de geração cidadã de dados e de cartografia da ação social, dando visibilidade a questões de interesse público e apoiando os processos de construção de sentidos e construção de visões de modos de vida mais sustentáveis. Com base nessas experiências, vislumbramos a importância de uma abertura do campo do design para processos democráticos, participativos, críticos e especulativos, que demandam uma atitude mais ativista, mais hacktivista.

Essas abordagens abrem o campo do design para a inovação social e para a produção do comum, em contraposição às práticas associadas aos processos de industrialização e consumo. Mais ainda, envolvem o design com a infraestruturação de espaços de interação sobre as controvérsias que formam a coisa pública (Ehn, 2008; Bjögvinsson et al, 2012).

À medida em que o Design se abre para o coletivo, o designer passa a atuar não mais para um público alvo, mas em colaboração com o público, em conjunto com atores empoderados e autônomos. Mais do que uma ferramenta de persuasão, de estimulo do consumo de produtos industriais, o design pode empoderar comunidades criativas na construção de um futuro comum e mais sustentável. Neste cenário, podemos vislumbrar a potência do Design como um agente de transformação social.

Com o desenvolvimento, popularização e disseminação das tecnologias cívicas e das plataformas de inovação social digital, novas oportunidades e desafios se abrem para designers que trabalham com design de informação, design de interação e design estratégico. Cada vez mais organizações não governamentais, coletivos informais, startups de empreendedorismo social, estão lançando mão dessas tecnologias para construir uma sociedade mais justa e democrática, dando oportunidade de participação e voz para as pessoas, cidadãos e comunidades em cenários de governo aberto e de ação comunitária. Essas organizações colaborativas estão ampliando a participação cidadã nos processos de tomada de decisão que determinam os contratos sociais que conformam a nossa realidade.

Uma nova cultura de design, aberta, colaborativa, ativista e participativa será necessária para promover a transição para modos de vida mais sustentáveis, para construção de uma sociedade mais justa e inclusiva. Assim poderemos vislumbrar novas formas de pensar e de fazer design, longe do determinismo e da eficiência industrial e mais perto da ação e da transformação social. 


\section{Referências}

BENEVIDES, M. A Cidadania Ativa. São Paulo: Ática, 1991.

BENKLER, Y. The Wealth of Networks: How Social Production Transform

Markets and Freedom. New Haven, Connecticut: Yale University Press, 2006

BINDER, T.; BRANDT, E.; HALSE, J. Democratic Design Experiments: Between

Parliament and Laboratory. CoDesign: International Journal of CoCreation in

Design and the Arts, v. 11, n. 3-4, 2015

BRIA, F.; SESTINI, F.; GASCO, M.; BAECK, P.; HALPIN, H.; ALMIRALL, E.; KRESIN, F. Growing a Digital Social Innovation Ecosystem for Europe: DSI Final Report.

European Union, 2014. Disponível em: <http://issuu.com/

digitalsocialinnovation/docs/dsireport7forwebsite7print>. Acessado em 30 jul. 2016.

CASTELLS, M. A Sociedade em Rede. São Paulo, Paz e Terra, 1999.

The Network Society: A Cross-Cultural Perspective. Cheltenham,

Edward Elgar, 2004.

CIPOLLA, C. \& MOURA, H. Social Innovation in Brazil Through Design Strategy. Design Management Journal, v. 6, n. 1, 40-51, out. 2012.

COLE, M.; LINDEQUE, P.; HALSBAND, C.; GALLOWAY, T.S. 2011. Microplastics as contaminants in the marine environment: $A$ review. Marine Pollution Bulletin, v. 62, n. 12, 2588-2597. http://www.sciencedirect.com/ science /article/pii/S0025326X11005133

DARDOT, P.; LAVAL, C. O comum: um ensaio sobre a revolução no século 21. Tenda, Universidade Nômade Brasil, 2014. (Tradução: Renan Porto) Disponível em: http://uninomade.net/tenda/3294/ Acessado em: 30/01/2017.

DEBORD, Guy. Theory of the Dérive. Internationale Situationniste, Vol. 2, 1958. Disponível em: http://www.cddc.vt.edu/sionline/si/theory.html. Acesso em 31 set 2016.

DEFORGES, Y. Por um Design Ideológico. Estudos em Design, v. 2, n. 1, 1994.

DISALVO, C. Adversarial Design. Kindle Edition. Cambridge, MA: The MIT Press. 2012

DISALVO, C. Design and the Construction of Publics. Design Issues, v. 25, n. 1 inverno 2009.

DUNNE, A. \& RABY, F. Speculative everything: design, fiction and social dreaming. Cambridge, London: The MIT Press, 2013. 
FRASCARA, J. 1997. User-Centred Graphic Design: Mass Communication And Social Change. Taylor \& Francis.

FUAD-LUKE, A. Design Activism: Beautiful Strangeness for a Sustainable World. Kindle Edition. London: Earthscan, 2009.

BRANDT, E; MESSETER, J., BINDER, T. Formatting Design Dialogues: Games and Participation. In: Binder T, Brandt E and Gregory J (Guest editors), CoDesign: International Journal of CoCreation in Design and the Arts, v. 4, n. 1, 51-64, mar. 2008.

GARLAND, K. First Things First. Manifesto. The Guardian, 24 jan. 1964.

HOWE, Jeff. Crowdsourcing: Why the Power of the Crowd Is Driving the Future of Business. New York: Crown Publishing Group, 2008.

JAMBECK, J.R.; GEYER, R.; WILCOX, C.; SIEGLER, T.R.; PERRYMAN, M.; ANDRADY, A.; NARAYAN, R.; LAW, K.L. Plastic waste inputs from land into the ocean. Science, v. 347, n. 6223, 768-771, 2015. Disponível em: <http:// science.sciencemag.org/content/347/6223/768.full-text.pdf>. Acessado em 30 jul. 2016.

KNIGHT FOUNDATION. Assessing Civic Tech: Case Studies and Resources for Tracking Outcomes. Report. Knight Foundation. March 2015

LATOUR, B. Reassembling the Social: An Introduction to Actor-NetworkTheory. Oxford University Press, 2005.

LATOUR, B.; WEIBEL, P. Making Things Public: Atmospheres of Democracy. Cambridge, MA: MIT Press, 2005.

LESSIG, L. Free Culture: How Big Media Uses Technology and Law to Lock Down Culture and Control Creativity. New York: Penguin Press. 2004 MALDONADO, Tomás. Design, Nature, and Revolution: Toward a Critical Ecology. New York: Harper \& Row. 1972

MANZINI, E. Design para a inovação social e sustentabilidade: comunidades criativas, organizações colaborativas e redes projetuais. Rio de Janeiro: Epapers, 2008.

MANZINI, E. Design When Everybody Designs: An Introduction to Design for Social Innovation. Massachusets: MIT Press. 2015

MARGOLIN, V. Introduction and Closing Essay. In: (Org.) Design discourse: history, theory, criticism. Chicago and London: The University of Chigago Press, 1989. 
MERONI, A. (Org.) Creative communities: People inventing sustainable ways of living. Milano: Edizioni POLI.design, 2007.

MERONI, A; FASSI, D.; SIMEONE, G. Design for Social Innovation as a form of Design Activism: An action format. In: SOCIAL FRONTIERS: THE NEXT EDGE OF SOCIAL INNOVATION RESEARCH, Glasgow Caledonian University, London Campus, November, 2013. Proceedings... London: Nesta, 2013

MURRAY, R.; CAULIER-GRICE, J; MULGAN, G. The Open Book of Social Innovation. London: Nesta, The Young Foundation. 2010 Disponível em: <http://www.nesta.org.uk/sites/default/files/the_open_book_of_social_inno vation.pdf >. Acessado em Abril, 2016.

O'Brien, M. Safecast Draws on Power of the Crowd to Map Japan's Radiation. PBS News Hour, 2011. Disponível em: <https://www.youtube.com/watch?v=pLdOkKAeROg>. Acessado em 30 jan. 2017.

PAPANEK, V. Design for the Real World: Human Ecology and Social Change. New York: Pantheon Books. 1971

PEREIRA JUNIOR, C. Tecnologias cívicas e inovação social digital: desafios para o design nos novos territórios de participação cidadã. Tese de Doutorado. Pontifícia Universidade Católica do Rio de Janeiro. Rio de Janeiro: PUC-Rio, 2017. PIMM, S. L.; JENKINS,C. N.; ABELL, R.; BROOKS, T. M.; GITTLEMAN, J. L.; JOPPA, L. N.; RAVEN, P. H.; ROBERTS, C. M.; SEXTON, J. O. The biodiversity of species and their rates of extinction, distribution, and protection. Science, v. $344, n$. 6187, 30 mai. 2014.

SELLE, Gert. Ideología y utopia del diseño. Barcelona, Editorial Gustavo Gili, 1973.

SHIRKY, Clay. Here Comes Everybody: The Power of Organizing Without Organizations. Penguin Press, Kindle Edition. 2008

SUROWIECKI, J. The wisdom of crowds: Why the many are smarter than the few and how collective wisdom shapes business, economies, societies and nations. New York: Doubleday, 2005.

TAPSCOTT, D. \& WILLIAMS, A.. Wikinomics: How Mass Collaboration Changes Everything. Kindle Edition. Atlantic Books, 2011

TEIXEIRA, A. Até onde vai a participação cidadã? In: REDE NACIONAL DE MOBILIZAÇÃO SOCIAL (COEP). Das ruas às redes:. 15 anos de mobilização social na luta contra a fome e a pobreza. Rio de Janeiro: COEP, 2008. 
THACKARA, J. In the bubble: designing in a complex world. Massachusetts Institute of Technology. 2005

THORPE, A. Design as Activism. In: CIPOLLA, C. \& PERUCCIO, P. (Org.) CHANGING THE CHANGE: DESIGN, VISIONS, PROPOSALS AND TOOLS, International Conference, Turin, Italy, July 2008. Proceedings... Torino: Allemandi Conference Press, 2008.

VITOUSEK, P. M., J. D. ABER, R. W. HOWARTH, G. E. LIKENS, P. A. MATSON, D. W. SCHINDLER, W. H. SCHLESINGER, AND D. G. TILMAN. Human alteration of the global nitrogen cycle: causes and consequences. Issues in Ecology, n. 1, 115, 1997. 


\section{Como citar}

PEREIRA JR, Clorisval G. Design e a construção de sentidos sobre questões de interesse público. Arcos Design. Rio de Janeiro: PPD ESDI - UERJ. Edição Especial Outubro 2017. p. 55-75. Disponível em: [http://www.e-publicacoes.uerj.br/index.php/ arcosdesign]

DOI 10.12957/arcosdesign.2017.30941

\section{(c) (i) () (2)}

A Revista Arcos Design está licenciada sob uma licença Creative Commons Atribuição - Não Comercial - Compartilha Igual 3.0 Não Adaptada. 